Research Article

\title{
A cross sectional study to evaluate the knowledge, attitude and practices of healthcare professionals on pharmacovigilance at Silchar medical college and hospital, Assam, India
}

\author{
Nishanta Thakuria $^{1 *}$, Dipjyoti Deka ${ }^{1}$, Devarsi Choudhury ${ }^{1}$, Nazar Ahmed ${ }^{2}$
}

\begin{abstract}
${ }^{1}$ Department of Pharmacology, Silchar Medical College and Hospital, Silchar-788014, Assam, India, ${ }^{2}$ Medical Officer, Gunjung Block Primary Health Center, Dima Hasao, Assam
\end{abstract}

Received: 19 May 2016 Accepted: 13 June 2016

\section{*Correspondence to:}

Dr. Nishanta Thakuria,

Email: dr.nyshanta@yahoo.co.in

Copyright: (C) the author(s), publisher and licensee Medip Academy. This is an openaccess article distributed under the terms of the Creative Commons Attribution NonCommercial License, which permits unrestricted noncommercial use, distribution, and reproduction in any medium, provided the original work is properly cited.

\begin{abstract}
Background: The primary objective of this study is to evaluate the knowledge, attitude and practice (KAP) of the doctors and students at Silchar medical college and hospital, Assam, India. Pharmacovigilance has gained worldwide importance and this study tries to widen its base in the north eastern part of India. The major task of pharmacovigilance programme is to collect and analyse the reports of adverse drug reactions and inform the potential risk.

Methods: The study was cross sectional, questionnaire based, designed to assess KAP of pharmacovigilance. 220 participated among whom 100 were post graduate (PG) students of various departments, 60 MBBS students and 60 interns.

Results: The difference in knowledge between the post graduates, interns and MBBS students were highly significant, though all of the groups scored in the moderate section. In the practice section, significant difference was found among the groups, but it is alarming to see that the scoring of the MBBS students fell in the poor category.

Conclusions: PGs, interns and MBBS students had a good attitude towards pharmacovigilance but knowledge and practice needs improvement. Constant motivation and support through seminars, workshops and adverse drug reporting will remarkably improve this programme.
\end{abstract}

Keywords: Adverse drug reaction, pharmacovigilance, interns, post graduates, KAP

\section{INTRODUCTION}

Spontaneous ADR (adverse drug reaction) reporting schemes have been a major source of information in pharmacovigilance. Spontaneous reporting can prevent the occurrence of new medicine tragedies and can improve the safety labelling of pharmaceutical products. ${ }^{1}$ ADRs are associated with a significant morbidity and mortality. Recent estimates suggest ADRs to be the fourth major cause of death in the United States (US). ${ }^{1}$ ADR is defined by the World Health Organization (WHO) as "a response to a drug which is noxious and unintended, and which occurs at doses normally used in man for prophylaxis, diagnosis, or therapy of disease or for the modification of physiologic function."2 According to Uppsala Monitoring Centre (UMC, WHO), Sweden; which maintains the international database of the adverse drug reaction reports, only $6-10 \%$ of all the ADRs are reported. ${ }^{3}$ In India, all healthcare professionals including doctors, nurses, and pharmacists can report an ADR by filling an ADR form of the Central Drugs Standard Control Organization. It is important for healthcare professionals to know how to report and where to report an $\mathrm{ADR}^{4}$

Pharmacovigilance is the science and activities relating to the detection, assessment, understanding and prevention of adverse effects or any other drug-related problems. 
ADR are rather a complex issue which requires special attention; they involve patients, Medical professionals, the Pharmaceuticals industries, drug regulatory agencies and academic scientist. ${ }^{5}$ Few studies had been carried out in different countries to assess the knowledge of Pharmacovigilance among the medical students and practitioners. In the U.K., 57\% of the medical schools assessed the students' knowledge on the yellow card scheme. In France, a survey which was conducted among medical residents showed that a majority lacked knowledge on pharmacovigilance. ${ }^{6}$ The major task of the Pharmacovigilance centre is to collect and analyse the reports and to inform stake holders of the potential risk when signals of new ADRs arise. Spontaneous reporting is also used by the pharmaceutical industry to collect information about their drugs. By means of a SRS it is possible to monitor all drugs on the market throughout their entire life cycle at a relatively low cost. The Pharmacovigilance study was initiated following the disaster caused by thalidomide in pregnant women in 1961 (WHO, 1969). Pharmacovigilance studies is becoming more important as new drugs are entering the market in jet speed and increase in number of drugs withdrawn because of ADRs. ${ }^{7}$

India ranks below $1 \%$ in terms of ADR reporting against the world rate of $5 \%$. To overcome this problem, the Ministry of Health and Family Welfare, Govt. of India, has initiated the National pharmacovigilance programme. The purpose of this programme is to collect the data, analyse it and to use the inferences to recommend informed regulatory interventions, besides communicating the risks to the health care professionals and the public. This programme is coordinated by the national pharmacovigilance centre at the Central Drugs Standard Control Organization (CDSCO) in New Delhi. The national centre is operating under the supervision of the national pharmacovigilance advisory committee, to recommend procedures and guidelines for regulatory interventions. This committee oversees the performance of two zonal, five regional and twenty six peripheral pharmacovigilance centres. The entire network works in coordination to improve the ADR reporting in our country. ${ }^{8}$

Although, India is participating in the program, its contribution to the UMC database is very little. This is essentially due to the absence of a vibrant ADR monitoring system and also due to a lack of the reporting culture among the health care workers. ${ }^{9}$

In order to improve the reporting rate, it is important to improve the knowledge, attitude and the practices (KAP) of the healthcare professionals with regards to the ADR reporting and the pharmacovigilance. This study was a step which was taken in that direction and it endeavoured at evaluating the baseline KAP of the doctors and students at Silchar Medical College and Hospital, Assam, India regarding the ADR monitoring and pharmacovigilance.
The objective of this study was to assess the knowledge, attitude and practices of pharmacovigilance among the MBBS students, interns and post graduate (PG) students of Silchar Medical College and Hospital, Silchar. And to compare the result among the three groups.

\section{METHODS}

The design of this study was cross sectional, questionnaire based.

Place of study was before initiating the study, proper approval was taken from the institutional ethical committee (IEC) and the chief superintendent of Silchar Medical College and Hospital. The Study was carried out in Silchar Medical College and Hospital, Assam, India among the PGs, MBBS students (who have passed $2^{\text {nd }}$ MBBS) and Interns working in the various departments.

The study instrument was predesigned questionnaire. The questionnaire was designed to assess knowledge, attitude and practice of pharmacovigilance among the study population.

The knowledge level was evaluated, based on the questions- 1 to 15 .

Attitude was evaluated as per their response to questions16 to 20 (except Q. 17) as question-17 has more than one right answer and answer may vary from participant to participant.

Practices were based on answers to the questions from 21 to 25 .

The questionnaire was distributed to 220 participants among whom 100 were PGs of various specialties, 60 MBBS students and 60 interns from Silchar Medical Students and Hospital, Assam, India. The participants were personally briefed about the questionnaire and they were requested to return the duly filled in forms within 30 minutes without consulting anyone.

The questionnaire was then evaluated. 1 point was awarded to each correct answer (max total-24 points). The knowledge level was evaluated, based on the questions- 1 to 15 , attitude was evaluated as per their response to questions- 16 to 20 (except Q. 17), and the practices, based on answers to the questions- 21 to 25 .

The questionnaires were then analysed by grading the respondents into 3 categories- poor, moderate and good as shown below.

The compiled data was then analysed by using the following statistical methods: Kruskal-Wallis test (nonparametric one way ANOVA), Dunn's multiple comparison test, Chi-square distribution test and data analyses was done by using graph-pad instat (version 
3.10 for Windows). The $\mathrm{P}$ value less than 0.05 were considered significant.

Table 1: Score range of the questionnaire.

\begin{tabular}{|lllll|}
\hline Parameters & & Score range & $\begin{array}{l}\text { Maximum } \\
\text { possible } \\
\text { score }\end{array}$ \\
\hline & Poor & Moderate & Good \\
\hline Knowledge & $0-5$ & $6-10$ & $11-15$ & 15 \\
\hline Attitude & $0-1$ & $2-3$ & 4 & 4 \\
\hline Practice & $0-2$ & $3-4$ & 5 & 5 \\
\hline
\end{tabular}

\section{RESULTS}

The questionnaire was distributed to 220 participants; among them 100 were PGs of various specialties, 60 were MBBS students, and 60 were interns of Silchar Medical College and Hospital, Silchar. The response rate was 90.9\% (PGs-90\%, interns $83.33 \%$ and students $100 \%$ ) i.e. 90 out of 100 post graduate students, 50 out 60 interns and 60 out of 60 MBBS students responded positively to the test.

Table 1 illustrates that in the knowledge section, mean score of the MBBS students were $7.56 \pm 1.68$, Interns were $7.46 \pm 1.93$, and the PGS were $9.28 \pm 2.56$. This highlights the fact that in the knowledge section, the scoring of the MBBS students, interns and the PGs fall moderate grouping. In the attitude section, the mean score of the students were $3.22 \pm 0.83$; interns were $3.24 \pm 0.79$; and the PGs were $3.33 \pm 0.75$. Thus for the attitude section, all the scoring were seen in the moderate section. For the practice section, the students scored 1.58 \pm 0.98 ; the Interns scored 3.06 \pm 1.10 and the PGs scored 3.71 \pm 0.94 . Thus, for the practice scoring, the students fell in the poor category, interns in the moderate and the PGs in the good category respectively.

Table 1: Descriptive statistics of knowledge, attitude and practice among MBBS students, interns and PGs of Silchar Medical College and Hospital, Assam, India.

\begin{tabular}{|lllll|}
\hline Components & Groups & $\mathbf{N}$ & MEAN* & SD* \\
\hline \multirow{5}{*}{ Knowledge } & Students & 60 & 7.56 & 1.68 \\
\cline { 2 - 5 } & Interns & 50 & 7.46 & 1.93 \\
\cline { 2 - 5 } & PGs & 90 & 9.28 & 2.56 \\
\cline { 2 - 5 } Attitude & Total & $\mathbf{2 0 0}$ & & \\
\hline & Students & 60 & 3.22 & 0.83 \\
\cline { 2 - 5 } & Interns & 50 & 3.24 & 0.79 \\
\cline { 2 - 5 } & PGs & 90 & 3.33 & 0.75 \\
\cline { 2 - 5 } Practice & Total & $\mathbf{2 0 0}$ & & \\
& Students & 60 & 1.58 & 0.98 \\
\cline { 2 - 5 } & Interns & 50 & 3.06 & 1.10 \\
\cline { 2 - 5 } & PGs & 90 & 3.71 & 0.94 \\
\cline { 2 - 5 } & Total & $\mathbf{2 0 0}$ & \\
\hline
\end{tabular}

The statistical analysis indicated that, the difference in knowledge between PGs and interns and between PGs and MBBS students was highly significant $(\mathrm{p}<0.001$ ) and the difference in knowledge between interns and MBBS students was not significant ( $p>0.05$ ).

Significant difference in practice was found between PGs and interns ( $\mathrm{p}<0.01)$. The difference between PGs and student was also highly significant $(\mathrm{p}<0.001)$.The difference between interns and student is highly significant $(\mathrm{p}<0.001)$.

The difference in attitude towards pharmacovigilance between PGs, interns and MBBS students was not significant.

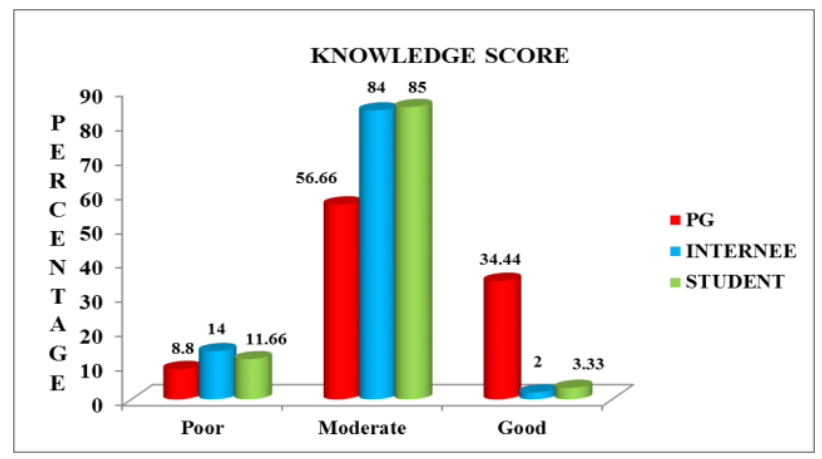

Figure 1: Knowledge score among PGs, MBBS students and interns.

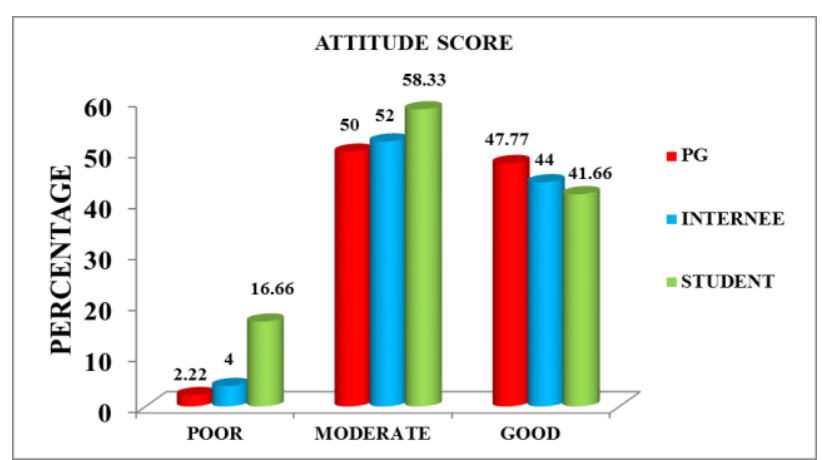

Figure 2: Attitude score among PGs, MBBS students and interns.

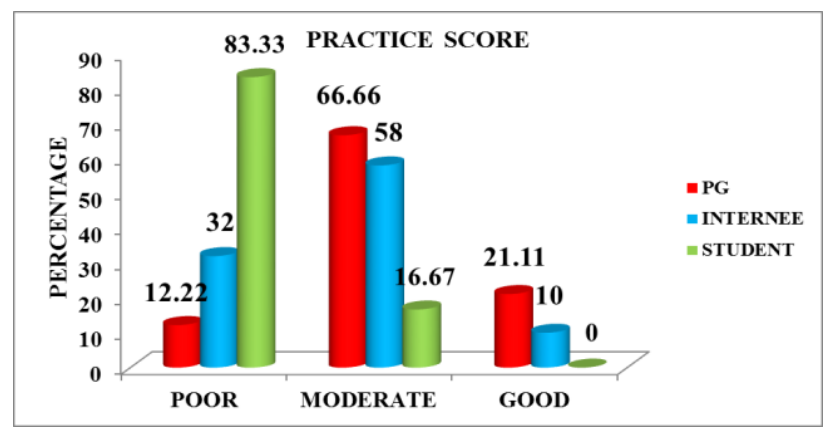

Figure 3: Practice score among PGs, MBBS students and interns. 


\section{DISCUSSION}

The innumerable social and economic consequences of adverse drug reactions nurture a need to actively involve health care professionals in the pharmacovigilance programme.

The main tasks of pharmacovigilance are the early detection of the adverse reactions and interactions, monitoring the frequency of the adverse reactions, identification of the risk factors for the adverse reactions and dissemination of the information which is required to improve the prescription of drugs. So, the most important clause of pharmacovigilance is the reporting of suspected adverse drug reactions. ${ }^{10}$

Many factors are associated with under reporting of the adverse drug reporting among the healthcare professionals. But basically, in order to improve the reporting rate, it is important to properly educate the healthcare professionals regarding ADR reporting/pharmacovigilance. The most appropriate time to do so is during the undergraduate and the postgraduate training of the doctors. This study was undertaken to evaluate the extent of the knowledge, attitude and practice of pharmacovigilance of the MBBS students, Interns and PGs of Silchar Medical College and Hospital, Silchar.

In this study, we assessed the knowledge, attitude and practice of pharmacovigilance among 3 different groups of respondents. This is because students, Interns and PGs can play a major role in interacting with patients in the clinical departments. From our present study, we found that, the mean knowledge score of PGs is (9.28 \pm 2.56$)$, MBBS student $(7.56 \pm 1.68)$ and interns $(7.46 \pm 1.93)$ contradicts the result obtained in the study by Hema NG et al where their mean knowledge score were 2.30 for final year students, 3.46 for PGs and 3.20 for the interns. ${ }^{11}$ In their study they found that the mean knowledge score is lowest among the MBBS students but in our present study carried out in Silchar Medical College and Hospital we found that the mean knowledge score is lowest among the interns.

The mean attitude score of postgraduate student is (3.33 \pm 0.75$)$, MBBS students $(3.22 \pm 0.83)$ and interns (3.24 \pm 0.79$)$ which is statistically not significant $(\mathrm{p}>0.05)$. It implies that the PGs, MBBS students and interns has same attitude towards the pharmacovigilance programme.

The mean practice score of MBBS students (1.58 \pm 0.98$)$ was lower than that of PGs $(3.71 \pm 0.94)$ and the interns $(3.06 \pm 1.10)$. Significant difference in Practice was found between $\mathrm{PGs}$ and interns $(\mathrm{P}<0.01)$. The difference between PGs and MBBS student was also highly significant ( $\mathrm{p}$ $<0.001)$. The difference between interns and students is highly significant $(\mathrm{p}<0.001)$.

The study by Shashikanth $\mathrm{C}$ et al even stated that most of the doctors and nurses were unaware of the pharmacovigilance programme of India and its coordinating centre. ${ }^{12}$ They mentioned that only $34.7 \%$ of the doctors and $16.7 \%$ of nurses knew where to report an ADR. Kamtane RA et al reported that ADR reporting is low among the medical professionals. ${ }^{13}$ There is a need for regular training and re-enforcement of guidelines for ADR reporting among health care personnel. The work by Gupta SK et al. ${ }^{4}$ stressed that there is a requirement for constant training and enactment of regulations for ADR reporting among healthcare professionals. Al-Arifi MN et al also highlights a lot of concern by physicians regarding possible legal consequences of reporting ADRs and some of them think that it's a time consuming process. ${ }^{14}$

In the study by Manjunath et al $89.39 \%$ of the students were aware of activities involved in pharmacovigilance. ${ }^{6}$ They reported that $91 \%$ of students were aware of the measures that have to be taken when an ADR is suspected, and similar was the result in a study by Deepak, et al who informed that $93 \%$ of the students had awareness about measures to be taken when an adverse drug reaction is suspected. ${ }^{15}$ Even our work showed that $84 \%$ of MBBS students had moderate knowledge about pharmacovigilance which is similar with these studies.

The work by Chopra D et al surprisingly reveal that only one tenth of the doctors $(10 \%)$ knew what should be reported. ${ }^{16}$ The majority $(74.4 \%)$ felt that reactions to new drug should be reported and also those reactions that are serious and unusual. Only one third (30\%) knew whom to report to and less than half $(30 \%)$ had actually ever reported an ADR. Even at our setup it was seen that only $21.11 \%$ of the PGS and $10 \%$ of the interns knew how practice of pharmacovigilance is done. A study by Kulkarni MD et al tells us the mean score for correct answers regarding knowledge of pharmacovigilance was $16.89 \% .^{17}$ It was an alarming situation which needed immediate attention of pharmacovigilance.

Sharma R, Kellarai A felt it was evident that the Interns and PGs were equally poor in ADR reporting, as $>65 \%$ had not reported any ADR. ${ }^{18}$ It is alarming and disheartening to note that, they have demonstrated the same trend seen among physicians and consultant prescribers. Our study even reported the same. A movement of teaching through seminars and workshops is the need of the hour as this has to be avoided in the upcoming days. The study by Raza A and Jamal $\mathrm{H}$ even found that out that pharmacy students had a high score as compared to the medical students, which necessitate the requirement of educational intervention at the undergraduate level to improve the knowledge and practice of pharmacovigilance. ${ }^{19}$ Overall; the KAP scores of the students were low. As ADRs is the fourth and sixth leading cause of deaths, therefore pharmacovigilance must be included in health care system.

Shankar R et al states all PGs of pharmacology (MD, $\mathrm{MSc}$ ) should have a thorough knowledge of pharmacovigilance. ${ }^{20}$ They should be active members of 
pharmacovigilance programmes in their medical colleges or teaching hospitals. They stated that in their institution, MSc students play an active role in the programme. The UMC's training programme is a good starting point. PG students, in other specialties, should also be made aware of pharmacovigilance, the need for and importance of reporting ADRs and the reporting procedure. They should be sensitized to ADR reporting during their residency training, with the help of the Pharmacology PGs, if necessary. These residents, in turn, can sensitize interns, undergraduate students and other healthcare professionals to the importance of pharmacovigilance.

In the study by Muraraiah S et al they felt that majority of the health care professionals have good knowledge about ADR reporting and understand the need for reporting. ${ }^{21}$ Lack of facilities and clinical knowledge about ADR discourages them from reporting. This showed that reports on the KAP varied considerably from regions to regions.

\section{CONCLUSION}

In our present study, we found that PGs, MBBS students and interns of Silchar Medical College and Hospital has good attitude towards pharmacovigilance but their knowledge and practice about Pharmacovigilance needs to be improved.

Hence we can conclude that there should be a teaching programme for the students and constant motivation of doctors by pharmacovigilance team to report about adverse drugs reaction in Silchar Medical College and Hospital, Silchar. This will improve the practice and knowledge of students about pharmacovigilance.

Funding: No funding sources

Conflict of interest: None declared

Ethical approval: The study was approved by the Institutional Ethics Committee

\section{REFERENCES}

1. Palaian S, Ibrahim MI, Mishra P. Health professionals' knowledge, attitude and practices towards pharmacovigilance in Nepal. Pharmacy Practice. 2011;9(4):228-35.

2. Arjun TN, Sudhir H, Gouraha A, Jain S, Chavan K, Dayma A. Assessment of knowledge, attitude and practice Related to pharmacovigilance among the Healthcare professionals in a teaching hospital in Central India: an questionnaire study World journal of pharmacy and pharmaceutical sciences. 2015;4(4):785-99.

3. World Health Organization. Safety of medicines: a guide to detecting and reporting adverse drug reactions. Geneva: 2002. WHO/EDM/QSM/2002;2.

4. Gupta SK, Nayak RP, Shivaranjani R, Vidyarthi SK. A questionnaire study on the knowledge, attitude, and the practice of pharmacovigilance among the healthcare professionals in a teaching hospital in South India. Perspectives in Clinical Research. 2015;6(1):45-52.

5. Vora MB, Barvaliya M. Knowledge, attitude and practices towards pharmacovigilance and adverse drug reactions in health care professional of tertiary care hospital, Bhavnagar. International Journal of Pharma Sciences and Research (IJPSR). 2014;5(11):820-6.

6. Manjunath SM, Raju NG, Someswara GM. A crosssectional study on the extent of pharmacovigilance awareness among fifth term medical students. IAIM. 2015;2(9):94-101.

7. Abubakar AR, Simbak NB, Haque M. A systematic review of knowledge, attitude and practice on adverse drug reactions and pharmacovigilance among doctors. Journal of Applied Pharmaceutical Science. 2014;4(11):117-27.

8. Prakash S. Pharmacovigilance in India. Indian J Pharmacol. 2007;39:123.

9. Inman WH. The attitudes to the adverse drugreaction reporting. $\mathrm{Br} \mathrm{J}$ Clin Pharmacol. 1996;41:433-5.

10. Gupta SK. Setting up a pharmacovigilance center, text book of pharmacovigilance. First edition, Jaypee brothers Medical Publishers. 2011;93-103.

11. Hema NG, Bhuvana KB, Sangeetha. Pharmacovigilance: the extent of awareness among the final year students, interns and postgraduates in a government teaching hospital. Journal of Clinical and Diagnostic Research. 2012;6(7):1248-53.

12. Shashikanth C, Parida A, Adiga S, Bairy KL. Knowledge, attitude and practice of health care professionals towards adverse drug reaction reporting in a South Indian teaching hospital. World Journal of Pharmaceutical Research. 2014;3(3):4263-71.

13. Kamtane RA, Jayawardhani V. Knowledge, attitude and perception of physicians towards adverse drug reaction (Adr) reporting: a pharmacoepidemiological study. Asian J Pharm Clin Res. 2012;5(3):210-4.

14. Al-Arifi MN, Mayet AY, Wajid S, Al-Saadi M, Babelghaith ISD, Ayoubi FZA. Knowledge, attitude and perception of physicians towards adverse drug reaction reporting at king Khalid university hospital, Riyadh, Saudi Arabia. Tropical Journal of Pharmaceutical Research. 2015;14(5):907-11.

15. Deepak P, Nagaral JV. Awareness of pharmacovigilance among medical students. International Journal of Recent Trends in Science and Technology. 2014;13(2):262-5.

16. Chopra D, Wardhan N, Rehan HS. Knowledge, attitude and practices associated with adverse drug reaction reporting amongst doctors in a teaching hospital. The International Journal of Risk and Safety in Medicine. 2011;23(4):227-32.

17. Kulkarni MD, Baig MS, Chandaliya KC, Doifode SM, Razvi SU, Sidhu NS. Knowledge, attitude and practice of pharmacovigilance among prescribers of Government medical college and hospital, 
Aurangabad (Maharashtra). International journal of pharmacology and therapeutics. 2013;3(3):10-8.

18. Sharma R, Kellarai A. Pharmacovigilance and adverse drug reaction reporting perspectives among interns and postgraduates of a teaching hospital. J Pharmacol Pharmacother. 2014;5(4):248-50.

19. Raza A, Jamal H. Assessment of knowledge, attitudes and practice among the medical and pharmacy students towards pharmacovigilance and adverse drug reactions in Abbottabad, Pakistan. J Pharmacovigilance. 2015;3:1-5.

20. Shankar R, Subish P, Mishra P, Dubey AK. Teaching pharmacovigilance to medical students and doctors. Indian J Pharmacol. 2006;38(5):316-9.

21. Muraraiah S, Rajarathna K, Sreedhar D, Basavalingu D, Jayanthi CR. A questionnaire study to assess the knowledge, attitude and practice of Pharmacovigilance in a paediatric tertiary care centre. J Chem Pharm Res. 2011;3(6):416-22.

Cite this article as: Thakuria N, Deka D,

Choudhury D, Ahmed N. A cross sectional study to evaluate the knowledge, attitude and practices of healthcare professionals on pharmacovigilance at Silchar medical college and hospital, Assam, India. Int J Basic Clin Pharmacol 2016;5:1481-9. 


\section{ANNEXURE-I}

Pharmacovigilance KAP Questionnaire

PI Initials:

/ Co-PI Initials:

Questionnaire no.:

Title: A cross sectional study to evaluate the Knowledge, Attitude and Practices of Healthcare Professionals on Pharmacovigilance in Silchar Medical College \& Hospital, Assam, India.

\section{Designation:}

Age (in years):

Qualification: MBBS Student/ MBBS/ PG Student (Specify Department)/ MD/ MS/ DM/ MCh/ PhD/ Others (Please Specify)

Place of work: Student/ Private practice/ Medical College hospital/ Private hospital/ Others (Please Specify)

Duration of joining Healthcare Profession (in years):

Mobile No.:

Email ID:

Instructions: - You are requested to give information to the best of your knowledge,

without any help from your friends, books, internet, etc.

- As you are not writing your name, your answers shall remain confidential.

1. Have you heard about Pharmacovigilance?
(a) Yes
(b) No

If Yes, where (tick one only):
(a) Academic curriculum
(b) Friends
(c) Teachers
(d) Internet
(e) Magazines
(g) Newspaper
(h) CMEs
(i) Conference
(j) Others (Please Specify)

2. Pharmacovigilance is defined as:
(a) The science of monitoring ADRs happening in a Hospital
(b) The process of improving the safety of Drugs
(c) The detection, assessment, understanding and prevention of adverse effects

(d) The science detecting the type and incidence of ADR after drug is marketed

3. What is the full form of ADR:

4. One of the following is the agency in Unites States of America involved in drug safety issues:
(a) American Society of Health System Pharmacists (ASHP)
(b) United States food and drug administration (US FDA)
(c) American Medical Association (AMA)
(d) American Pharmaceutical Association (APA)

5. The National Coordination Centre, Pharmacovigilance Programme of India is located in: 

(a) Mumbai
(b) Bangalore
(c) Chennai
(d) Pondicherry
(e) Ghaziabad
(f) Lucknow

6. The WHO approved International Pharmacovigilance Centre is in:
(a) London
(b) Geneva
(c) Uppsala
(d) New York
(e) Paris

7. Are you aware of existence of a peripheral Pharmacovigilance centre in South of Assam?
(a) Yes
(b) No

If yes, then where is it located:

8. One of the following is a major risk factor for the occurrence of maximum adverse drug reactions:
(a) Arthritis
(b) Renal failure
(c) Visual impairment
(d) Vasculitis

9. In India which Regulatory body is responsible for monitoring of adverse drug reactions?
(a) Central Drugs Standard Control Organization
(b) Indian Institute of Sciences
(c) Pharmacy Council of India
(d) Medical Council of India

10. Can you name the Antidiabetic drug that was banned in India in 2010 due to its cardiovascular adverse effects:
(a) Metformin
(b) Pioglitazone
(c) Regular Insulin
(d) Rosiglitazone
(e) Glimepiride
(f) Acarbose

11. Which method is commonly employed by pharmaceutical companies for Pharmacovigilance of new drugs once they are launched in the market?
(a) Post Marketing Surveillance (PMS) Studies
(b) Meta-analysis
(c) Regression analysis
(d) Population studies

12. In India, a serious adverse drug reaction report should be sent to regulatory body within how many calendar days?
(a) 1 day
(b) 7 days
(c) 14 days
(d) 1 month

13. Which of the following scales is most commonly used to establish the causality of an adverse drug reaction?
(a) Hartwig scale
(b) Naranjo algorithm
(c) Schumock and Thornton scale
(d) Karch and Lasagna scale

14. Which one of the following is the 'WHO online database' for reporting adverse drug reactions?
(a) ADR advisory committee
(b) Medsafe
(c) Vigibase
(d) Med watch

15. The healthcare professionals responsible for reporting ADR in a hospital is/are
(a) Doctor
(b) Pharmacist
(c) Nurses
(d) All of the above

16. Do you think reporting adverse drug reaction is necessary?
(a) Yes
(b) No

17. Which among the following factors discourage you from reporting Adverse Drug Reactions? (Any one only)

(a) Non-remuneration for reporting 
(b) Lack of time to report ADR

(c) A single unreported case may not affect ADR database

(d) Difficult to decide whether ADR has occurred or not

18. Do you think reporting is a professional obligation for you?
(a) Yes
(b) No
(c) Don't know
(d) Perhaps

19. Do you think Pharmacovigilance should be taught in detail to healthcare professionals?
(a) Yes
(b) No

20. What is your opinion about establishing ADR monitoring centre in every hospital?
(a) Should be in every hospital
(b) Not necessary in every hospital
(c) One in a city is sufficient
(d) Depends on number of bed size in the hospitals

21. Have you ever reported any adverse drug reaction to any centre?
(a) Yes
(b) No

22. Have you ever seen an Adverse Drug Reaction Reporting Form?
(a) Yes
(b) $\mathrm{No}$

23. Have you ever seen any patient experiencing an adverse drug reaction?
(a) Yes
(b) No

24. Do you follow any approach to prevent adverse drug reaction?
(a) Yes
(b) No
If yes, please specify:

25 . Have you ever read any article on prevention of adverse drug reactions?
(a) Yes
(b) No

Date:

Place:

(Signature) 